\title{
Central/peripheral vascularization and resistance index at Doppler ultrasound examination of thyroid nodules. Are they useful to differentiate between benign and malignant pathology?
}

\section{Pacenza NA ${ }^{1}$, Rosmarin $M^{1}$, Blanc E1, Serrano $S^{2}$, Cejas $C^{3}$, Sforza ${ }^{1}$, Serrano $L^{4}$, Campero $\mathrm{A}^{3}$, Frid $\mathrm{S}^{1}$, Faingold $\mathrm{MC}^{1}$, Brenta $\mathbf{G}^{1}$ \\ Departments of Endocrinology and Metabolism ${ }^{1}$, Pathology ${ }^{2}$, Radiology ${ }^{3}$ and Surgery ${ }^{4}$ of "Dr César Milstein" Hospital, Buenos Aires, Argentina e-mail: napacenza@yahoo.com.ar}

\section{INTRODUCTION}

Thyroid Doppler ultrasound (TDUS) is highly used in the evaluation of thyroid nodules (TN) ${ }^{1}$. Malignant thyroid pathology has been more frequently associated with central vascularization of such nodules. There is controversy regarding to the usefulness of the Resistance Index (RI) in the assessment of TN 2,3.

\section{OBJECTIVE}

Our aim was to analyze the utility of vascularization characteristics and RI at TDUS in the distinction of benign and malignant TN.

\section{PATIENTS AND METHODS}

Characteristics of peripheral vascularization (PV) or central and peripheral vascularization (C/PV), and RI (estimated by blood flow speed at the prominent artery at TDUS) were analyzed in all patients who underwent thyroid surgery and had an US-guided fine needle aspiration biopsy (FNAB) performed in our institution since June 2011 to November 2015.

\section{RESULTS}

3 Autoimmune Thyroiditis

10 Nodular goiter

11 Nodular adenomatous goiter

14 Follicular adenoma

2 Hürthle cell adenoma patients

60 women and 2 men Mean age $68.2+/-6.8$ (Range: 50 to $85 \mathrm{y} / 0$ )
40 with Benign pathology

22 with Malignant pathology
17 Papillary carcinoma

1 Follicular carcinoma

1 Hürthle cell carcinoma

2 Medullary carcinoma

1 Lymphoma
15 Patients had 2 TN with FNAB

Total: 77 TN evaluated

(50 Benign and 27 Malignant)

20 Benign (64.5\%)

\begin{tabular}{|c|c|c|}
\hline & & RI \\
\hline \multirow{2}{*}{$\begin{array}{c}\text { Thyroid } \\
\text { nodules } \\
(\mathrm{n}=77)\end{array}$} & Benign & $0.59+/-0.09^{*}$ \\
\hline & Malignant & $0.60+/-0.10^{*}$ \\
\hline
\end{tabular}

Higher RI: Lymphoma (0.80)

Higher RI. Lymphoma (0.80)

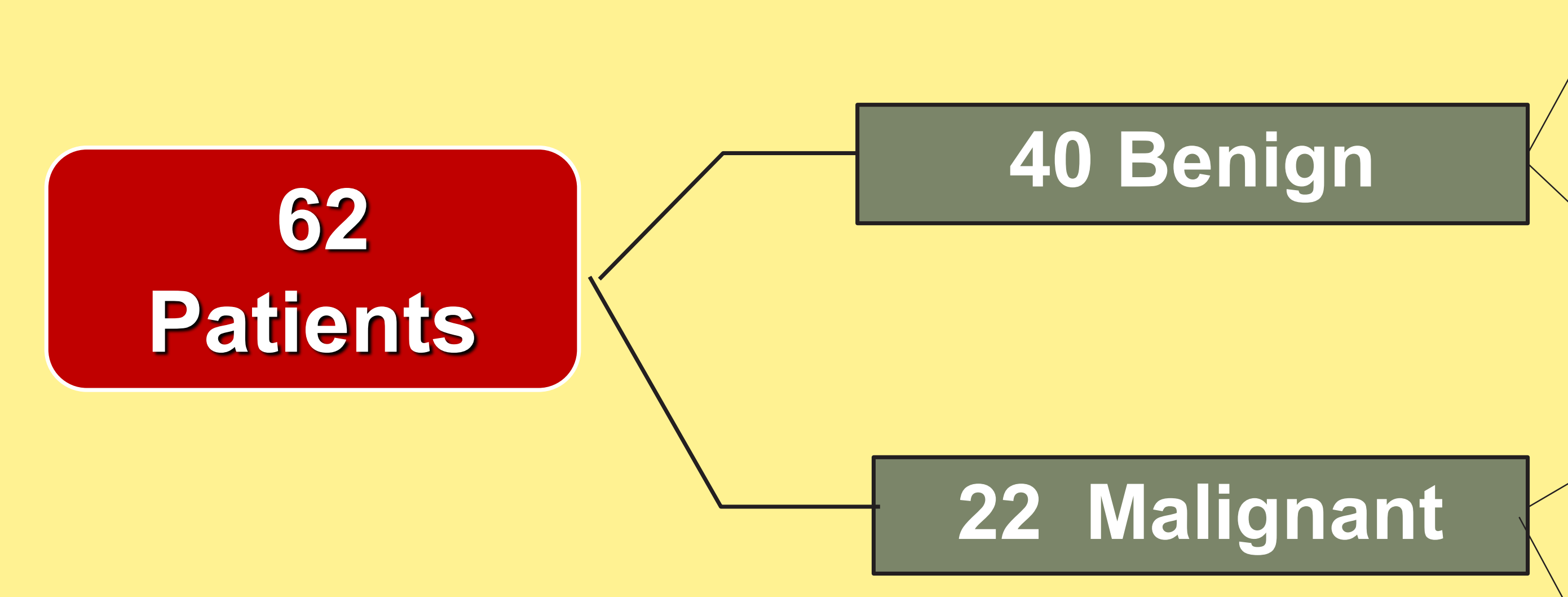

\section{6 with PV $(40 \%)^{*}$}

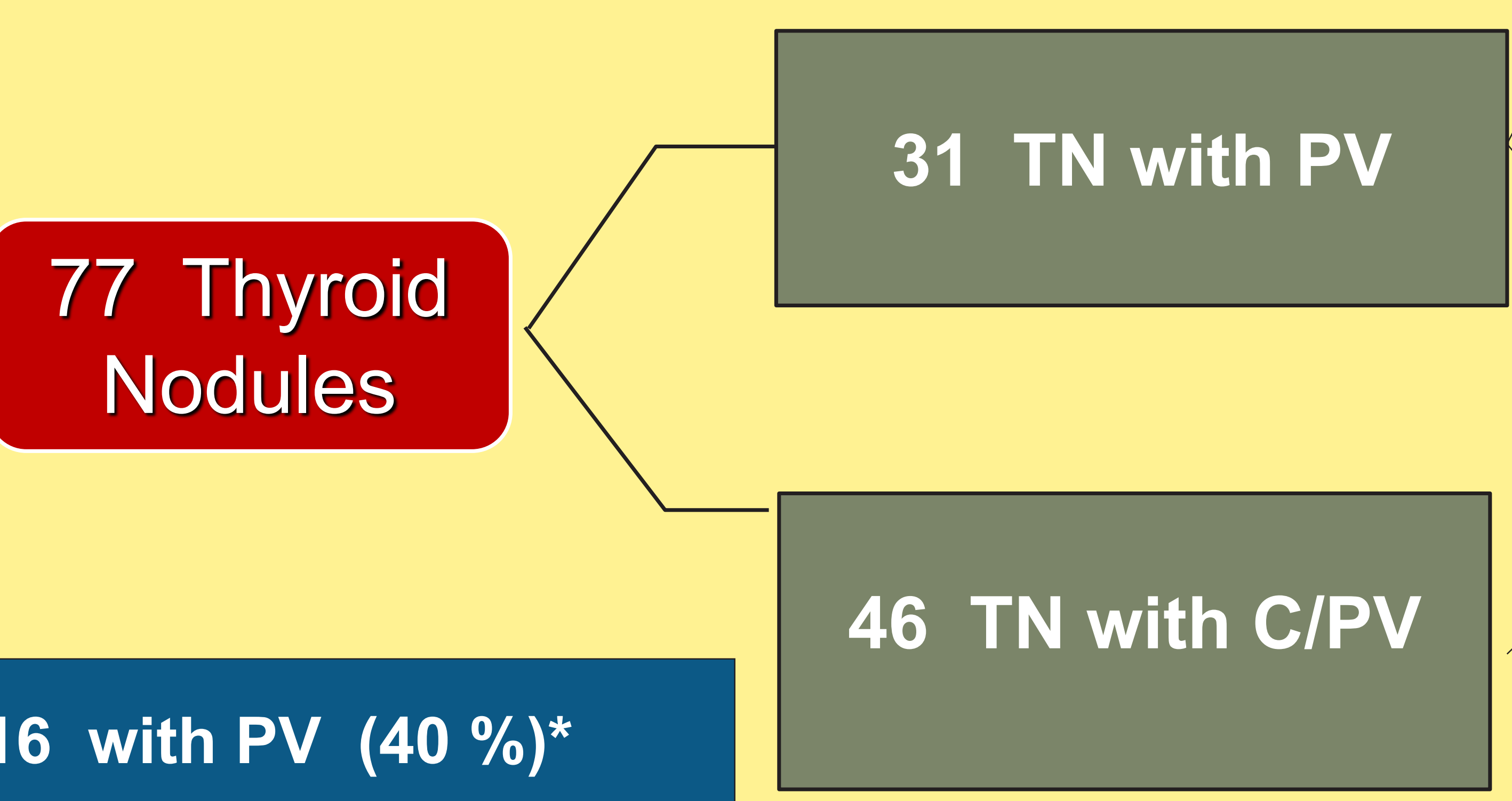

24 with C/PV (60\%)*

10 with PV $(45.5 \%)^{*}$

12 with C/PV (54.5\%)*
20 Benign $(64.5 \%)$

11 Malignant $(35.5 \%)^{*}$

30 Benign (65.2\%)

16 Malignant $(34.8 \%)^{*}$
* Non significant difference

Sensitivity of C/PV for malignant pathology was $34.8 \%$ and specificity was $64.5 \%$.

\section{CONCLUSION}

In our experience, characteristics of vascularization (peripheral or central and peripheral) and the RI of TN at TDUS alone were not useful to distinguish between benign and malignant pathology in our population.

\section{BIBLIOGRAPHY}

1) Risk of Malignancy in Nonpalpable Thyroid Nodules: Predictive Value of Ultrasound and Color-Doppler Features. Papini E. JCEM 87(5):1941-46, 2002.

2) Vascular Pattern and Spectral Parameters of Power Doppler Ultrasound as Predictors of Malignancy Risk in Thyroid Nodules. Bakhshaee M. Laryngoscope 118: 2182-86, 2008.

3) Thyroid Ultrasound Features and Risk of Carcinoma: A Systematic Review and Meta-Analysis of Observational Studies. Remonti L. Thyroid 25 (5):, 2015. 